\title{
Modeling and optimization of business processes and process systems under conditions of uncertainty
}

\author{
Alexander G. Madera \\ Professor, Department of Mathematics of the Faculty of Economics \\ National Research University Higher School of Economics \\ Address: 20, Myasnitskaya Street, Moscow, 101000, Russian Federation \\ E-mail:amadera@hse.ru
}

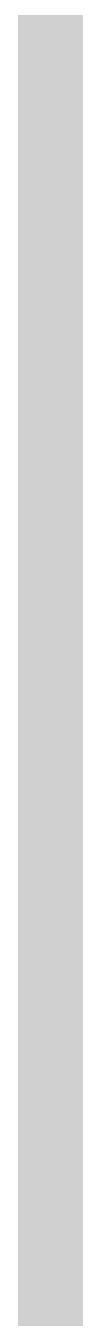

\begin{abstract}
This paper is devoted to mathematical modeling and optimization of business processes and process systems under conditions of uncertainty. At present, modeling of business processes is mainly descriptive, which does not allow quantitative modeling and optimization in the design of processes and process systems. In addition, the existing methods of decision-making in business processes are based on the assumption that the decisive factors are deterministic. Despite uncertainty of the real processes caused by the uncertainty of future costs of resources, the market environment, economy, finances, etc., the factors of an uncertain future are either not taken into account, or are believed to be the same as those observed currently.

In this paper, a stochastic interval mathematical optimization model is developed. This model allows us to simulate in a quantitative way the business processes and process systems in which they take place, taking into account the uncertainties of the future state of the economy, finances, market environment, costs of resources, as well as future realization of chances and risks related to the productive, supporting, and service processes. The criterion for optimality of the model is the maximization of the smallest deviation of the projected chances and risks, which makes it possible to make the best decision in the case that the most unfavorable conditions for the business process occur in the future. The criterion of optimality adopted in the mathematical model takes into account not only the uncertainty of the future state of the economy, finance, and market environment, but also the psychology of decision-making and the subjective nature of judgments and estimates. We present a concept and method for estimating the inductive (logical, subjective) probabilities of the occurrence of uncertain projected business process factors.

The models and methods developed in the paper make it possible to carry out mathematical modeling and optimization of business processes in a variety of activities without restrictions on the complexity of the structural model of the business process, the qualitative and quantitative composition of the connections in the process systems. On their basis, a software package for the quantitative design of business processes and process systems under conditions of uncertainty can be developed.
\end{abstract}


Key words: business process, process system, conditions of uncertainty, mathematical model, optimization, interval stochastic model, probability, optimization criterion, chances, risks.

Citation: Madera A.G. (2017) Modeling and optimization of business processes and process systems under conditions of uncertainty. Business Informatics, no. 4 (42), pp. 74-82.

DOI: 10.17323/1998-0663.2017.4.74.82.

\section{Introduction}

$\mathrm{Q}$ uantitative design of business processes and corresponding process systems requires appropriate quantitative methods of modeling and optimization. However, modeling of processes and process systems in all fields of activity (manufacture, service, maintenance, support, supply, logistics, supply chains) is nowadays mainly qualitative and descriptive. The models are presented using either verbal, textual, graphical, or other kinds of descriptions or notations that form a stream of works, resources, and information. In the existing literature on business processes, their modeling is assumed to encompass the so-called regulation, documenting, and supporting document flow, and the optimization is understood as re-engineering, which includes a series of actions aimed at coordinating and amending the processes [1, 2]. However, all types of organizational instructions or actions based on some qualitative criteria of an optimum cannot be, in fact, regarded as optimization. Optimization should be based on mathematical analysis and the search for an extremum of some quantitative measure of optimality. Using qualitative analysis alone, it is impossible to ensure that an optimal solution is found.

In spite of the high demand for the development of mathematical methods of modeling and optimization of business processes and process systems, the design of such processes and systems is still mainly performed using qualitative approaches. This conclusion follows from the clearly insufficient number of published works on mathematical methods of modeling and process optimization (as pointed out, e.g., in [3]), as well as from the dire lack of case studies on real companies that practice quantitative design, modeling and optimization of their business processes $[4,5]$. We note that while the publications $[3,6-14]$ present some mathematical models of business processes, these ad hoc results are only applicable to the particular cases considered in those papers. Moreover, the majority of publications consider business processes under fully determined conditions only, i.e., on the assumption that all the underlying factors of the business processes are known exactly and unambiguously.

In practice, however, all the factors that determine the business processes and process systems are usually uncertain. Among those factors are the future state of the economy, finances, market demand and supply, future prices of the resources and energy, investment amounts, demand for new products, chances, risks, and future financial stability of the organizational units comprising the process system. In reality, the parameters of both the present and the future necessarily involve uncertainty. Therefore we need to incorporate uncertainty conditions in the methods of modeling and business process optimization in order to adequately describe reality.

In this paper, we develop a mathematical model for the optimization of business processes and process systems under uncertainty conditions using stochastic interval factors obeying the uniform probability distribution. The models and methods of modeling and optimization developed in this paper can serve 
as a foundation for the qualitative design of processes and process systems, development of the relevant software, and can be employed in practical applications in the areas of manufacture, support, supply, maintenance, customer service, logistics, supply chains among others.

\section{Structural and mathematical models of the process elements}

A structural model of a process and a process system includes the set of interacting organizational units that are modeled by the process elements and connections between them. Within each process element, various activities are performed that are aimed at the same common goal of creating the ultimate end-product possessing value for the consumer. A process element receives a flow of resources (industry factors) at the input. These resources are transformed into either intermediate products or end-products at the output of the element.

According to [2], there are the following types of business processes and corresponding elements (Figure 1):

$\downarrow$ productive, or main, processes and elements (Figure 1a) - processes that increase both the value and cost of the end-product or intermediate product, by an amount equal to the cost of the product's manufacture. Within a productive element, the input flows of the material factors, energy, and labor are transformed into the output product (intermediate product, semi-finished product, unfinished production, the end-product of the overall process);

$\downarrow$ supporting processes and elements (Figure 1b) - processes in which the product is neither produced or changed either qualitatively or quantitatively, value is not added, in contrast with the added value due to the energy and labor used in the production activities. Within a supporting element, the amounts of the production factors and products at the input and output of the element are equal to each other. Examples of supporting activities include loading, unloading, delivery of the factors and products, storage, documentation paperwork, and so on;

$\downarrow$ service processes and elements (Figure 1c) - processes that increase both the cost and the value for the consumer for which they are prepared to pay. Similar to a productive element, a service element adds value to the product due to the spending of production factors, energy, and labor in the course of performing the services. At the same time, the amounts of the product at the input and output of the service element are equal, as they are in a supporting element. The service works may include any processing of the end-product done at the consumer's request and for which the consumer is prepared to

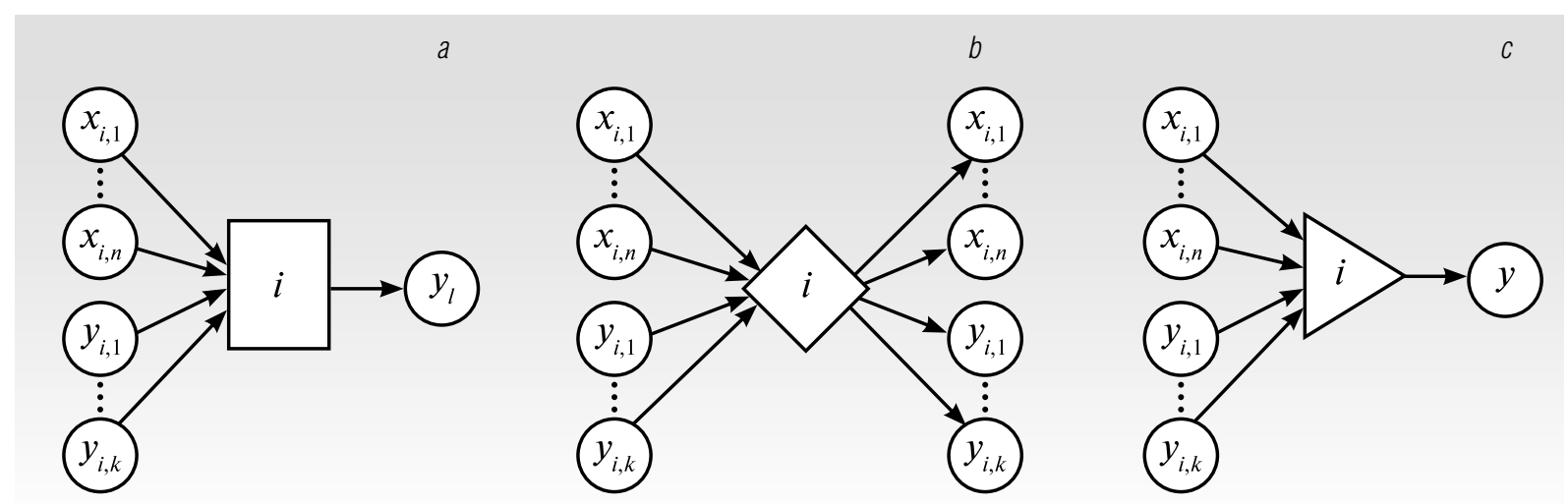

Fig. 1. Structural models for the (a) productive, (b) supporting, and (c) service elements 
pay: custom packaging, sorting, labeling, improving the appearance, direct delivery to the consumer, etc.

The input flows of each element include both the exogenous flows of resource purchased outside the process (set $\boldsymbol{X}$ ), and the endogenous flows of products produced within prior elements of the same process (set $\boldsymbol{Y}$ ) that are fed, for the production purposes, into other elements of the same process. Exogenous and endogenous flows in the sets $\boldsymbol{X}$ and $\boldsymbol{Y}$ are numbered independently and continuously throughout the entire structure of the process system.

Let us consider the structural model of a process system of a sample business process (Figure 2). The flows of exogenic and endogenic resources are shown by circles with resource amounts marked inside them ( $x$ for exogenic, $y$ for endogenic resources); the incoming resources and/or products are shown by arrows; the production elements are shown by rectangles (Figure 1a), the supporting elements are shown by diamonds (Figure $1 b$ ), and the service elements are shown by triangles (Figure 1c). The structural model in Figure 2 contains two supporting elements (1 and 6), four production elements (2, 3, 4, 5 and 7), and a single service element (8). The exogenic resources are purchased in the amounts $x_{1}, x_{2}, x_{3}, x_{4}, x_{5}$ outside the process; the endogenic products are produced in the amounts $y_{1}, y_{2}, y_{3}, y_{4}$ within the process elements 2, 3, 4 and 5. The end-product of the entire business process is the output of the production element 7 ; it is produced in the amount $y_{5}$ and it serves as the input for the service element 8 , in which service works are performed but $y_{6}=y_{5}$.

The works to create the end-product in the amount $y_{5}$ are performed the following way. Resource $x_{1}$ and part $x_{2}$ of the resource $x_{2}^{\prime}$ (such that $\left.x_{2}=x_{2}^{\prime}+x_{2}^{\prime \prime}\right)$ are fed into the warehouse element 1, and from there to the output of the production elements 3 and 4 . Part $x_{2}^{\prime \prime}$ of the resource $x_{2}$, and resource $x_{3}$ are directly fed into the production element 2 , where they are used to create a product in the amount $y_{1}$. A part of this product, $y_{1}^{\prime}$ (such that $\left.y_{1}=y_{1}^{\prime}+y_{1}^{\prime \prime}\right)$, enters the production element 4 , and the remaining part $y_{1}^{\prime \prime}$ is fed into the production element 5. Coming out, the production elements 3 and 4, the products $y_{1}$ and $y_{3}$ together with $x_{5}$ serve as the input for the production element 7 , where they are transformed. The product $y_{4}$ after the production element 5 enters the warehouse together with the resource $x_{4}$. After that, they are fed as the input into the production element 7 , where, together with the products $y_{2}, y_{3}$, and the resource $x_{5}$, they are transformed into the end-product of the business process $y_{5}$. The latter undergoes service actions in the service element 8 , where it acquires properties demanded and paid for by the consumer.

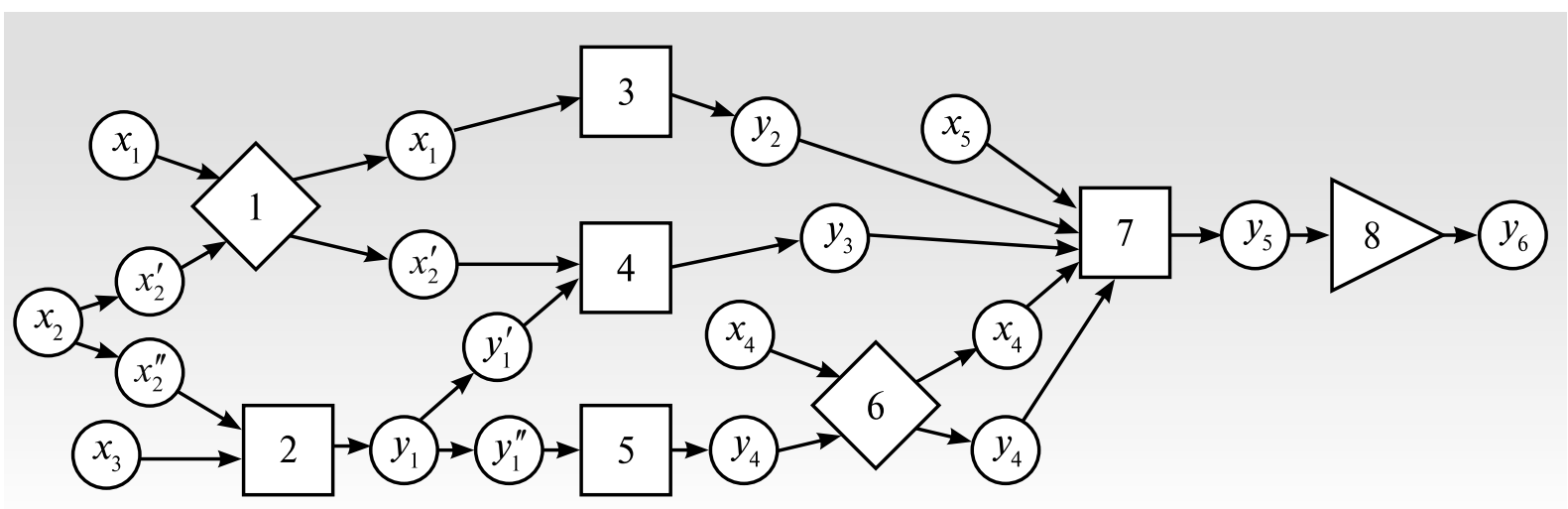

Fig. 2. A structural model of the business process and process system

(1, 6 - supporting elements, 2, 3, 4, 5, 7-production elements, 8 - service element) 
The mathematical model of the $i$-th production element (Figure 1a), which is fed the ordered sets of exogenic, $\boldsymbol{X}_{i}$, and endogenic, $\boldsymbol{Y}_{i}$, flows of resources $\left\{x_{i, 1}, x_{i, 2}, \ldots, x_{i, n}\right\} \in \boldsymbol{X}_{i} \subset \boldsymbol{X}$ and $\left\{y_{i, 1}, y_{i, 2}, \ldots, y_{i, k}\right\} \in \boldsymbol{Y}_{i} \subset \boldsymbol{Y}$, is a multifactor production function $[15,16]$, which can be represented in the following natural form:

$$
y_{l}=f_{i}\left(x_{i, 1}, x_{i, 2}, \ldots, x_{i, n} ; y_{i, 1}, y_{i, 2}, \ldots, y_{i, k}\right),
$$

where $y_{l} \in \boldsymbol{Y}$ - the amount of the product that was produced within the $i$-th element.

In contrast to the production elements, where production factors are transformed into a qualitatively new product at the output, the supporting elements (Figure $1 b$ ) perform actions to support the production process, whereas within the service elements (Figure 1c), service works are carried out upon the created end-product. The production factors are not spent within the supporting or service elements during various actions; however, the energy, labor, and means of labor are spent during the works upon the end-product, but this does not change its amount. While the supporting processes do not add value to the produced products, the service processes, on the contrary, add value to the end-product by ensuring the properties requested by the consumer and providing services paid for by the consumer.

Therefore, the mathematical models of the supporting elements can be represented by identity production functions of the production factors' transformation into themselves,

$f_{i}\left(x_{i, 1}, x_{i, 2}, \ldots, x_{i, n} ; y_{i, 1}, y_{i, 2}, \ldots, y_{i, k}\right)=x_{i j}, j=1,2, \ldots, n$, $f_{i}\left(x_{i, 1}, x_{i, 2}, \ldots, x_{i, n} ; y_{i, 1}, y_{i, 2}, \ldots, y_{i, k}\right)=y_{i j}, j=1,2, \ldots, k$,

The mathematical models of the service elements are then represented by production functions that transform the production factors and the end-product in the amount of $y$ into a product of the same amount, $f\left(x_{i, 1}, x_{i, 2}, \ldots, x_{i, n} ; y\right)=y[15,16]$.

\section{A mathematical model of a business process and process system under conditions of uncertainty}

To adequately describe real business processes, mathematical models should take into account the uncertainty of the future state of economy, finances, market demand prices for production factors and energy, volumes of investments, chances, risks, and other factors of uncertainty (see Section 1), as well as the psychological factors that affect the decisions, opinions, and estimates [17-21]. Uncertainty is modeled by the stochastic interval factors that are uniformly distributed inside the intervals whose boundaries are determined by inductive (logical, or subjective) probability $[16,20-25]$. To set up the optimization model, we need to define the quantitative optimization criterion and constraints on the range of acceptable solutions, $\boldsymbol{D}$ [26].

Optimization criterion for the mathematical model. The uncertain events that might be crucial in the future could be divided into two types: events that could be favorable for the business process (chances) - high profits, goal achievement, obtaining the planned results and unfavorable events (risks) such as losses, insufficient profit, failures, bankruptcies, etc. As shown in [16, 24], to ensure the best solutions, the optimization criterion should maximize the chances and minimize the risks. The complex criterion "chances-risks" $C h \& R[16$, 24] satisfies these conditions and is defined as

$$
C h \& R=\beta_{C h} C h-\beta_{R}|R|,
$$

where $C h$ and $R$ - the total projected chances and risks relevant to the process under consideration;

$\beta_{C h}, \beta_{R} \in[0,1]$ - the coefficients of relative importance of the chances and risks.

The values of the total chances $C h \in M$ and risks $R \in \boldsymbol{M}$ (where $\boldsymbol{M}$ set includes $L$ chances and $K$ risks) are determined [16, 24] 
as sums of the products of the quantitative measures of chances (income, profit, cash) $M_{C h, k},(k=1,2, \ldots, L)$ by risks (losses, defaults, damages) $M_{R, k},(k=1,2, \ldots, K)$ by the measures of their possible realization, or probabilities, $P_{C h, k}$ and $P_{R, k}$, i.e.

$$
C h=\sum_{k=1}^{L} M_{C h, k} P_{C h, k}, \quad R=\sum_{k=1}^{K} M_{R, k} P_{R, k} .
$$

Here the qualitative measures of the $k$-th chance or risk are stochastic intervals, varying within the intervals $M_{C h, k} \in\left[\underline{M}_{C h, k}, \bar{M}_{C h, k}\right]$, $M_{C h, k} \in\left[\underline{M}_{R, k}, \bar{M}_{R, k}\right]$, where $\underline{M}_{C h, k}, \bar{M}_{C h, k}$ and $\underline{M}_{R, k}, \bar{M}_{R, k}$ are the lower and upper bounds of the intervals of the quantitative measures of the chances and risks, which are calculated according to the rules of the interval arithmetic [27].

To obtain the best solution relevant for the business process that will maximize the chances and minimize the risks at the same time, the optimization criterion "chances-risks" $C h \& R$ must be maximized. This means we have to find a solution under uncertainty conditions such that we ensure the maximum possible difference between the lower bound for chances Ch and the upper bound for risks $\bar{R}[16,24]$ for any $\omega \in \Omega$ (where $\omega$ is an elementary event, and $\Omega$ is the space of elementary events). We obtain the following optimization criterion for business processes:

$$
\max \{C h \& R\}=\max \left\{\beta_{C h} \underline{C h}-\beta_{R}|\bar{R}|\right\},
$$

where $\underline{C h}=\sum_{k=1}^{L} \underline{M}_{C h, k} P_{C h, k}, \bar{R}=\sum_{k=1}^{K} \bar{M}_{R, k} P_{R, k}$.

Constraints of the mathematical optimization model. Constraints of the mathematical model are determined by the budget and set the conditions for the value of the total expenses for the process activities. These expenses should not exceed the finances available for the business process. Let us denote the amounts of the purchased exogenic produc- tion factors by $\{x\}=\left\{x_{1}, x_{2}, \ldots, x_{m}\right\} \in \boldsymbol{D}, x_{i} \geq 0$, and their costs by $c_{C h, i}$ and $c_{R, i},(i=1,2, \ldots m)$. Considering that the costs of the production factors are uncertain and given by stochastic intervals, and that they vary within the intervals $c_{C h, i}(\omega) \in\left[\underline{c}_{C h, i}, \bar{c}_{C h, i}\right]$ and $c_{R, i}(\omega) \in\left[\underline{c}_{R, i}, \bar{c}_{R, i}\right]$, $\bar{c}_{C h, i} \leq \underline{c}_{R, i}$ with the lower and upper bounds $\underline{c}_{C h, i}, \bar{c}_{C h, i}$ and $\underline{c}_{R, i}, \bar{c}_{R, i}$, we obtain the expressions for the total expenses for the purchase of the production factors for each $\omega \in \Omega$ :

$$
C_{C h}(\omega)=\sum_{i=1}^{m} c_{C h, i}(\omega) x_{i}, \quad C_{R}(\omega)=\sum_{i=1}^{m} c_{R, i}(\omega) x_{i} .
$$

Since both the expenses and the funding volumes of the business process are stochastically uncertain, we should consider the budget constraint in a probabilistic sense, namely through the probabilities of satisfying the budget constraints (inequalities), which should be lower than certain threshold values $p_{C h}$ and $p_{R}$ set by the owner of the business process [28] and the business analysts. Therefore, the constraints for the chances and risks can be written down as follows:

$P\left\{C_{C h}(\omega) \leq I_{C h}(\omega)\right\} \geq p_{C h}, P\left\{C_{R}(\omega) \leq I_{R}(\omega)\right\} \geq p_{R}$,

where $I_{C h}(\omega) \in\left[\underline{I}_{C h}, \bar{I}_{C h}\right]$ and $I_{R}(\omega) \in\left[\underline{I}_{R}, \bar{I}_{R}\right]$, $\bar{I}_{C h} \leq \underline{I}_{R}$ - the stochastic interval volumes of the funding of the business process;

$P\{\cdot\}$ - the inductive (subjective, or logical) probabilities.

The stochastic interval mathematical optimization model. The stochastic interval mathematical optimization model of a business process with uncertain parameters is set up as follows: we need to find the amounts of the production factors $\{x\}=\left\{x_{1}, x_{2}, \ldots x_{m}\right\} \in \boldsymbol{D}$, $x_{i} \geq 0, i=1,2, \ldots m$, that provide the maximum value of the criterion "chances-risks" (1) and satisfy the probabilistic constraints for the chances and risks, i.e.:

$$
\max _{x}\{C h \& R\}=\max _{x}\left\{\beta_{C h} \underline{C h}-\beta_{R}|\bar{R}|\right\},
$$

$P\left\{C_{C h}(\omega) \leq I_{C h}(\omega)\right\} \geq p_{C h}, \quad P\left\{C_{R}(\omega) \leq I_{R}(\omega)\right\} \geq p_{R}$. 
To find the optimal solution for the given optimization model under the conditions of the stochastic interval uncertainty, we need to rewrite the probabilistic constraints (2) as the corresponding deterministic equivalents [29].

The equivalent deterministic mathematical optimization model. Let us note that the stochastic interval costs of the production factors $c_{C h, i}(\omega), c_{R, i}(\omega)$ and the funding volumes $I_{C h}(\omega)$, $I_{R}(\omega), \omega \in \Omega$ are uniformly distributed over respective intervals. By Lyapunov's central limit theorem [30], their sums, which are equal to the total expenses, are normally distributed with the expected values

$$
m\left(C_{C h}\right)=\sum_{i=1}^{m} m\left(c_{C h, i}\right) x_{i}, m\left(C_{R}\right)=\sum_{i=1}^{m} m\left(c_{R, i}\right) x_{i}
$$

and dispersions

$$
\sigma^{2}\left(C_{C h}\right)=\sum_{i=1}^{m} \sigma^{2}\left(c_{C h, i}\right) x_{i}^{2}, \sigma^{2}\left(C_{R}\right)=\sum_{i=1}^{m} \sigma^{2}\left(c_{R, i}\right) x_{i}^{2},
$$

where

$$
\begin{gathered}
m\left(c_{C h, i}\right)=\left(\underline{c}_{C h, i}+\bar{c}_{C h, i}\right) / 2, m\left(c_{R, i}\right)=\left(\underline{c}_{R, i}+\bar{c}_{R, i}\right) / 2, \\
\sigma^{2}\left(c_{C h, i}\right)=\left(\underline{c}_{C h, i}-\bar{c}_{C h, i}\right)^{2} / 12, \sigma^{2}\left(c_{R, i}\right)=\left(\underline{c}_{R, i}-\bar{c}_{R, i}\right)^{2} / 12 .
\end{gathered}
$$

By the theorem [29], we rewrite the probabilistic inequalities in the constraints (2) in a deterministic form and thus obtain the final equivalent deterministic mathematical optimization model:

$$
\begin{gathered}
\max _{\{x\}}\{C h \& R\}=\max _{\{x\}}\left\{\beta_{C h} \frac{C h}{\beta_{R}}-\beta_{R}|\bar{R}|\right\}, \\
m\left(C_{C h}\right)+k_{C h} \sqrt{\sigma^{2}\left(C_{C h}\right)+\sigma^{2}\left(I_{C h}\right)} \leq m\left(I_{C h}\right), \\
m\left(C_{R}\right)+k_{R} \sqrt{\sigma^{2}\left(C_{R}\right)+\sigma^{2}\left(I_{R}\right)} \leq m\left(I_{R}\right), \\
x_{i} \geq 0, i=1,2, \ldots, m,
\end{gathered}
$$

where $k_{C h}, k_{R}$ are the quantiles of the standard normal distributions;

$m\left(I_{C h}\right), m\left(I_{R}\right)$ and $\sigma^{2}\left(I_{C h}\right), \sigma^{2}\left(I_{R}\right)$ are expected values and dispersions for the stochastic interval volumes of funding:

$$
\begin{gathered}
m\left(I_{C h}\right)=\left(\underline{I}_{C h}+\bar{I}_{C h}\right) / 2, m\left(I_{R}\right)=\left(\underline{I}_{R}+\bar{I}_{R}\right) / 2, \\
\sigma^{2}\left(I_{C h}\right)=\left(\underline{I}_{C h}-\bar{I}_{C h}\right)^{2} / 12, \sigma^{2}\left(I_{R}\right)=\left(\underline{I}_{R}-\bar{I}_{R}\right)^{2} / 12 .
\end{gathered}
$$

The deterministic mathematical optimization model so obtained belongs to the class of general problems of nonlinear programming. Its optimal solution can be obtained using specialized software packages, such as NEOS, AMPL, MATLAB, MathOptimizier, GALAHAD, and MS Excel. From the optimal solution $\left\{x^{*}\right\}=\left\{x_{1}^{*}, x_{2}^{*}, \ldots, x_{m}^{*}\right\}$ obtained numerically, we can find the optimal values for all the factors of the business process and process system: the amount and cost of the end-product, the amounts and costs of the intermediate products obtained as the outputs of each element, incomes and profits under different projected future conditions, etc.

\section{Method for estimating the inductive probabilities of projected events}

Probabilities of future events (the state of economy, finances, risks, chances, etc.) should be estimated using the concept of inductive probability, because the projected events are unique, and the concepts of the classical or the statistical probabilities are not applicable. Unique events are not the random objects that classical probability theory deals with, because such events do not satisfy the necessary conditions of being indefinitely repeatable, uniform, and possessing a stable frequency in a large number of trials under identical conditions [20-24].

The concept and method for estimating the inductive probabilities $P(A)$ for the events $\{A\}=\left\{A_{1}, A_{2}, \ldots A_{n}\right\}$ to occur are developed in [21] and lead to the projections that are considerably more accurate. The method is based both on the statistical data on the projections of the relevant events over past periods of time and on new information about the present trends. The data for the past periods of time characterize 
the errors made by the person who performed the projections of the events and estimated their probabilities. The data derived from the history of the events' development and information about the current trends can be used to calculate the corrections. These two types of data allow one to derive two matrices: the matrix of projecting errors made by the given person, $\mathcal{L}$, and the matrix of corrected projections, $\mathcal{M}$, calculated by the use of current information. As shown in [21], the unknown vector $P(A)$ describing the probability that the projected events will occur is the eigenvector of the complete projection error matrix $\mathcal{K}=\mathcal{M} \cdot \mathcal{L}$ corresponding to the eigenvalue 1, i.e. $P(A)=\mathcal{K} \cdot P(A)$.

\section{Conclusion}

The stochastic interval mathematical optimization model proposed in this paper allows for the modeling of optimal business processes and optimal structures and parameters of the process systems under conditions of uncertainty reflecting the state of the future economy, finances, market environment, demand for new products, costs of the production factors, sale price of the end-product, investments volumes, future chances and risks, and so on. The structural model of a production system may include the productive, supporting, and service elements that cover the entire range of activities performed during various business processes that transform the input factors into the output products. The mathematical models and methods developed in this paper facilitate the mathematical modeling and optimization of various business processes and process systems without limitations regarding the complexity, qualitative and quantitative composition of the process elements, or the complexity of the structure of the process system. They can serve as a foundation for the development of software packages for the quantitative design of business processes and complex process systems under conditions of uncertainty.

\section{References}

1. Robson M., Ullah P. (1996) A practical guide to business process re-engineering. Hempshire: Gower.

2. Harrington H.J., Esseling K., van Nimwegen H. (1997) Business process improvement workbook: Documentation, analysis, design, and management of business process improvement. N.Y.: McGraw-Hill.

3. Vergidis K., Tiwari A., Majeed B. (2008) Business process analysis and optimization: Beyond reengineering. IEEE Transactions on Systems, Man, and Cybernetics. Part C (Applications and Reviews), vol. 38, no. 1, pp. 69-82.

4. Stock J.R., Lambert D.M. (2001) Strategic logistics management. Boston: McGraw-Hill.

5. Shapiro J.F. (2001) Modeling the supply chain. Duxbury, CA: Thomson Learning.

6. van der Aalst W.M.P. (1998) The application of Petri nets to workflow management. Journal of Circuits, Systems and Computers, vol. 8, no. 1, pp. 21-66.

7. Hofacker I., Vetschera R. (2001) Algorithmical approaches to business process design. Computers \& Operations Research, no. 28, pp. 1253-1275.

8. Koubarakis M., Plexousakis D. (2002) A formal framework for business process modelling and design. Information Systems, vol. 27, no. 5, pp. 299-319.

9. Valiris G., Glykas M. (2004) Business analysis metrics for business process redesign. Business Process Management Journal, vol. 10, no. 4, pp. 445-480.

10. Seuring S. (2013) A review of modeling approaches for sustainable supply chain management. Decision Support Systems, vol. 54, no. 4, pp. 1513-1520.

11. Wibig M. (2013) Dynamic programming and genetic algorithm for business processes optimization. International Journal of Intelligent Systems and Applications, vol. 5, no. 1, pp. 44-51. 
12. Sawicki P., Sawicka H. (2014) Logistics process improvement using simulation and stochastic multiple criteria decision aiding. Procedia - Social and Behavioral Sciences, no. 111, pp. 213-223.

13. Zhang Q., Shah N., Wassick J., Helling R., van Egerschot P. (2014) Sustainable supply chain optimisation: An industrial case study. Computers \& Industrial Engineering, no. 74, pp. 68-83.

14. Ahmadikatouli A., Motameni H. (2015) Enrichment of object oriented Petri net and object $Z$ aiming at business process optimization. International Journal of Advanced Computer Science and Applications, vol. 6, no. 7, pp. 13-19.

15. Kleiner G.B. (1986) Proizvodstvennye funktsii: Teoriya, metody, primenenie [Production functions: Theory, methods, application]. Moscow: Finance and Statistics (in Russian).

16. Madera A.G. (2015) Matematicheskoe modelirovanie i optimizatsiya biznes-protsessov na osnove kompleksnogo kriteriya "shansy - riski" [Mathematical modeling and optimization of business processes based on an integrated criterion of chances and risks]. Russian Management Journal, vol. 13, no. 4, pp. 51-68 (in Russian).

17. Kozielecki J. (1979) Psikhologicheskaya teoriya resheniy [Psychological decision theory]. Moscow: Progress (in Russian).

18. Plous S. (1993) The psychology of judgment and decision making. N.Y.: McGraw-Hill, Wesleyan University.

19. Werth L. (2004) Psychologie für die wirtschaft. Grundlagen und anwendungen. Berlin: Spectrum Akademischer Verlag.

20. Madera A.G. (2014) Interval'no stokhasticheskaya neopredelennost' otsenok v mnogokriterial'nykh zadachakh prinyatiya resheniy [Interval stochastic uncertainty of estimates in multiple criteria decision making problems]. Artificial Intelligence and Decision Making, no. 3, pp. 105-115 (in Russian).

21. Madera A.G. (2016) Metod opredeleniya veroyatnostey prognoziruemykh sobytiy pri prinyatii resheniy [Method for of probabilities of the projected events when making decisions]. Artificial Intelligence and Decision Making, no. 2. pp. 38-45 (in Russian).

22. Carnap R. (1971) Logical foundations of probability. Chicago: The University of Chicago Press.

23. de Finetty B. (1974) Bayesinism: Its unifying role for both the foundations and applications of statistics. International Statistical Review, no. 42, pp. 117-130.

24. Madera A.G. (2014) Riski i shansy: neopredelennost', prognozirovanie i otsenka [Risks and chances: Uncertainty, forecasting and estimation]. Moscow: Krasand (in Russian).

25. Madera A.G. (2016) Estimating the probability of forecasted events. International Journal of Accounting and Economics Studies, vol. 4, no. 1, pp. 76-80.

26. Madera A.G. (2009) Modelirovanie i prinyatie resheniy v menedzhmente [Modeling and decision making in management]. Moscow: LKI (in Russian).

27. Alefeld G., Herzberger J. (1983) Introduction to interval computations. N.Y.: Academic Press.

28. ISO/IEC 15288:2002. System engineering - System life cycle processes.

29. Liu B. (2002) Theory and practice of uncertain programming. Heidelberg: Physica-Verlag.

30. Feller W. (1970) An introduction to probability theory and its applications. N.Y.: John Wiley. 